\title{
Intrathecal pre-administration of fentanyl effec- tively suppresses formalin evoked c-Fos expression in spinal cord of rat
}

[La pré-administration intrathécale de fentanyl supprime efficacement l'expres-

sion de c-Fos provoquée par le formol dans la moelle épinière du rat]

Tadashi Nakamura MD, Mayumi Takasaki MD PhD

Purpose: To investigate whether the timing of intrathecal administration of the opioid analgesic fentanyl, alters noxious stimulusevoked neuronal activity in the rat spinal cord.

Methods: A 5\% formalin solution was used as the noxious stimulant. For the pretreatment group, a dose of 0.001 to $0.5 \mu \mathrm{g}$ of fentanyl was injected intrathecally ten minutes prior to formalin injection. Early and late post-treatment groups received $0.0 \mathrm{I}$ to 0.5 $\mu \mathrm{g}$ fentanyl, five and $60 \mathrm{~min}$ after formalin injection respectively. The effect of fentanyl was confirmed with naloxone. The level of cFos expression was determined in each treatment group to indicate neuronal activity.

Results: Pretreatment and early post-treatment groups showed suppression of c-Fos activity compared to the vehicle $(P<0.01)$. The late post-treatment group showed no difference in c-Fos activity compared to the vehicle $(P=N S)$. Pretreatment with fentanyl showed the most profound suppression of c-Fos expression ( $P$ $<0.0$ I). In addition, pretreatment injection showed a greater suppression of c-Fos activity in the deep ( $14.6 \%$ of control) compared to the superficial laminae ( $32.7 \%$ of control; $P<0.0$ I), whereas the early post-treatment group showed a universal decrease in c-Fos activity (49.2\% of control in laminae I and II, $50.4 \%$ of control in laminae III and IV and 5I.8\% of control in laminae $\mathrm{V}$ and $\mathrm{VI}$ ). Naloxone reversed the action of fentanyl on c-Fos activity.

Conclusion: Inasmuch as: 1) c-Fos expression can be equated with behavioural changes; 2) injection of formalin is an appropriate model of surgical trauma; and 3) animal data can be transports to humans, these results suggest that fentanyl would be an effective pre-emptive analgesic.
Méthode : Une solution de formol à $5 \%$ a servi de stimulus nocif. Dans le groupe de prétraitement, une dose de 0,00 I à 0,5 $\mu \mathrm{g}$ de fentanyl a été administrée en injection intrathécale dix minutes avant l'injection de formol. Dans les groupes de post-traitement hâtif et tardif, on a donné de 0,0 l à 0,5 $\mu \mathrm{g}$ de fentanyl, cinq et 60 min après le for$\mathrm{mol}$, respectivement. L'effet du fentanyl a été confirmé par la naloxone. Le niveau d'expression de c-Fos a été déterminé dans chaque groupe pour indiquer l'activité neuronale.

Résultats : L'examen des rats des groupes de prétraitement et de post-traitement hâtif, comparés au groupe ayant reçu l'excipient, a montré une suppression de l'activité de c-Fos $(P<0,01)$. Le groupe de post-traitement tardif, comparé à l'excipient, ne présentait aucune différence d'activité de c-Fos $(P=N S)$. Le prétraitement au fentanyl a permis la suppression la plus profonde de l'expression de c-Fos $(P<$ $0,01)$. De plus, l'injection de prétraitement a entrainé une suppression plus importante dans les lames profondes ( $14,6 \%$ des témoins) comparées aux lames superficielles (32,7 \% des témoins; $P<0,01)$, tandis que le post-traitement hâtif a provoqué une baisse générale de l'activité de c-Fos (49,2 \% des témoins dans les lames I et II, 50,4\% des témoins dans les lames III et IV et $51.8 \%$ des témoins dans les lames $V$ et VI). La naloxone a renversé l'action du fentanyl sur l'activité de c-Fos.

Conclusion : Étant donné : I) que l'expression de c-Fos peut être mise en équation avec les changements comportementaux; 2) que l'injection de formol constitue un modèle approprié de traumatisme chirurgical et 3) que les données animales peuvent être extrapolées à l'humain, ces résultats suggèrent que le fentanyl serait un analgésique préventif efficace

Objectif: Vérifier si le moment choisi pour l'administration intrathécale de l'analgésique opioïde fentanyl agit sur l'activité nerveuse induite par un stimulus nocif dans la moelle épinière du rat.

From the Department of Anesthesiology, Miyazaki Medical College, Miyazaki, Japan.

Address correspondence to: Dr. Tadashi Nakamura, Department of Anesthesiology, Miyazaki Medical College, 5200 Kihara, Kiyotake,

Miyazaki 889-1692, Japan. Phone: 81-985-85-2970; Fax: 81-985-85-7179; E-mail: zenigata@postl.miyazaki-med.ac.jp

Accepted for publication February 19, 2001. 
$\mathrm{N}$

OXIOUS input from damaged tissue can induce changes in somatosensory processing leading to hyperalgesia and allodynia.

The alteration of nociception is due to sensitization of peripheral and central nociceptors immediately after tissue injury. ${ }^{l}$ These sensitizations are associated with interactions of neurotransmitters and induce nuclear protein c-Fos in affected sensory neuron. ${ }^{2}$ As a result of sensitization, neuraxial drugs such as opioids have limited ability to suppress the exaggerated responses to noxious stimuli and spontaneous pain. ${ }^{3}$ To prevent this from occurring, pretreatment with opioids and/or local anesthetics are recommended for preemptive analgesia.

The correct use of these drugs and their effects on neuronal cell activity during the treatment process have yet to be investigated fully. Although it is assumed that long-acting drugs such as morphine reduce cell activation throughout the course of nociceptive transmission, the effective duration of shortacting drugs such as fentanyl is unclear. Fentanyl, a $\mu$-opioid receptor agonist, is widely used in perioperative pain management. It is reported to have a prolonged pre-emptive effect despite its short duration. ${ }^{4,5}$ The basis of fentanyl activity and how it relates to cell activity or sensitization is not well known. In addition, the importance of timing of administration, pre- or post-noxious stimuli, needs to be determined.

In this study, we administered fentanyl at different times and to cover different periods and determined neuronal cell activity by measuring the level of expression of the immediate early gene product, c-Fos, in the spinal cord of rats.

\section{Materials and methods}

Animal preparation

This study was approved by the Animal Care Committee of Miyazaki Medical College. All experiments were performed on male Sprague-Dawley rats weighing 350 to $360 \mathrm{~g}$. Intrathecal catheters were placed in each rat two weeks prior to the start of experiments. Rats were anesthetized by intraperitoneal injection of ketamine (Sankyo, Tokyo, Japan) at a dose of $10 \mathrm{mg} \cdot \mathrm{kg}^{-1}$. A slit was made in the atlanto-occipital membrane and an $8 \mathrm{~cm}$ length of catheter (PE-10, Clay Adams, New Jersey, USA) was inserted into the subarachnoid space as far as the lumbar spinal cord. ${ }^{6}$ All rats were maintained in a 12-hr light-dark cycle and allowed free access to food and water for one to two weeks. Rats with neurological disturbances were excluded from following experiments. Postmortem verification was performed to confirm that the intrathecal catheter was correctly placed at the lumbar enlargement of all rats before immunohistochemical processing.

\section{Noxious stimuli}

After intraperitoneal injection of $40 \mathrm{mg} \cdot \mathrm{kg}^{-1}$ of pentobarbitone (Abbott, Illinois, USA), $150 \mu \mathrm{L}$ of $5 \%$ formalin solution was injected $s c$ into the plantar surface of the right hind paw of each rat using a 30 -gauge needle.

\section{Fentanyl injection}

Sixty-five rats were randomly assigned to four groups. Fentanyl was diluted in saline solution to a volume of $10 \mu \mathrm{L}$ and injected intrathecally. The catheter was then flushed with $10 \mu \mathrm{L}$ of saline. Rats in group I (pretreatment group) received $0 \mu \mathrm{g}$ (control) $(n=5), 0.001 \mu \mathrm{g}$ $(n=5), 0.01 \mu \mathrm{g}(n=5), 0.1 \mu \mathrm{g}(n=5)$, or $0.5 \mu \mathrm{g}(n=5)$ of fentanyl (Sankyo, Tokyo, Japan) through the intrathecal catheter ten minutes before formalin injection.

Rats in group II (early post-treatment group) received $0 \mu \mathrm{g}$ (control) $(n=5), 0.01 \mu \mathrm{g}(n=5)$, or $0.5 \mu \mathrm{g}$ $(n=5)$ of fentanyl intrathecally, five minutes after formalin injection. Rats in group III (late post-treatment group) received $0 \mu \mathrm{g}$ (control) $(n=5)$ or $0.5 \mu \mathrm{g}(n=5)$ of fentanyl intrathecally, $60 \mathrm{~min}$ after formalin injection.

If suppression of c-Fos expression occurred, an opioid antagonist was administered to confirm that fentanyl was directly responsible for the effects observed. In detail, an additional five rats in groups I and II were given $2 \mathrm{mg} \cdot \mathrm{kg}^{-1}$ of naloxone (Sankyo, Tokyo, Japan) ip five minutes before $0.5 \mathrm{ug}$ of fentanyl injection. The same dose of naloxone was injected repeatedly every $30 \mathrm{~min}$ until sacrifice. Group IV included pretreatment rats $(n=5)$ that received $2 \mathrm{mg} \cdot \mathrm{kg}^{-1}$ of naloxone five minutes after the formalin injection ( $15 \mathrm{~min}$ after $0.5 \mu \mathrm{g}$ of fentanyl administration), and followed by naloxone injections at 30 -min intervals. This group was used to determine the effect of fentanyl during the early phase of formalin stimulation only.

\section{Immunohistochemistry}

Two hours after formalin injection, all rats were sacrificed by intraperitoneal injection of $100 \mathrm{mg} \cdot \mathrm{kg}^{-1}$ pentobarbitone. Rats were perfused transcardially, initially with $200 \mathrm{~mL}$ of saline and then with $500 \mathrm{~mL}$ of $4 \%$ paraformaldehyde containing $0.1 \mathrm{M}$ phosphate buffer for $30 \mathrm{~min}$. The spinal cord at the lumbar enlargement was quickly removed and post-fixed in $4 \%$ paraformaldehyde for one hour. After post-fixation, it was cryoprotected in $0.1 \mathrm{M}$ phosphate buffer containing $10 \%$ and $30 \%$ sucrose solutions for one hour and overnight, respectively. Frozen sections $(50 \mu \mathrm{m})$ were cut in the transverse plane using a cryostat and col- 
lected as free-floating sections for immunohistochemical analysis. Alternate sections were incubated in $3 \%$ hydrogen peroxide for ten minutes followed by $1 \%$ Triton X-100 for $30 \mathrm{sec}$ at room temperature. The sections were washed with $0.1 \mathrm{M}$ phosphate buffered saline (PBS) and incubated with 10\% goat serum (Nichirei SAB kit, Tokyo, Japan) for $20 \mathrm{~min}$ at room temperature. The sections were then incubated with primary polyclonal anti-c-Fos antiserum (Santa Cruz Biotechnology, California, USA), diluted 1:5000 in PBS with bovine serum albumin, for $24 \mathrm{hr}$ at $4 \mathrm{C}$. The streptavidin-biotin-horseradish peroxidase method (Histofine kit, Nichirei, Tokyo, Japan), using a diaminobenzidine as a chromogen intensified with Co, was employed to visualize the c-Fos immunoreactive nuclei. Tissue sections were mounted on gelatinsubbed slides, air-dried and protected with coverslips.

\section{c-Fos expression}

Tissue sections were first examined under dark-field illumination to determine segmental level and to delineate Rexed's laminae. ${ }^{8}$ Ten sections were taken in order of level from the L4 and L5 spinal segments of each rat. Stained cells were examined with bright-field illumination and counted with a camera lucida attachment to determine c-Fos expression by a person blinded to the treatment. The average numbers of stained nuclei in ten sections per rat were recorded. To determine regional specificity of c-Fos expression, gray matter was divided into four regions: laminae I and II, III and IV, V and VI, and others. The level of c-Fos expression in each group was expressed as mean \pm SEM.

\section{Data analysis}

Statistical comparisons of the fentanyl doses in each laminar region in each group were performed by oneway analysis of variance (ANOVA), followed by Scheffe's test. Comparisons between doses and laminar regions in each group were made by two-way ANOVA, and comparisons among the groups were made by one-way ANOVA, followed by Scheffe's test. $P<0.01$ was considered statistically significant.

\section{Results}

Cells in which c-Fos staining was detected showed a dark blue nucleus and scant staining of the cytoplasm. Rats injected with formalin showed numerous c-Fos positive cells in the L4 and L5 spinal cord ipsilateral to the formalin-injected hind paw. The majority of c-Fos expression in formalin and vehicle $(0 \mu \mathrm{g}$ of fentanyl) injected rats in all groups was located in laminae I and II $(54.3 \%$ of the total number of c-Fos expressing cells), and in laminae V and VI (32\%) (Figure lA).

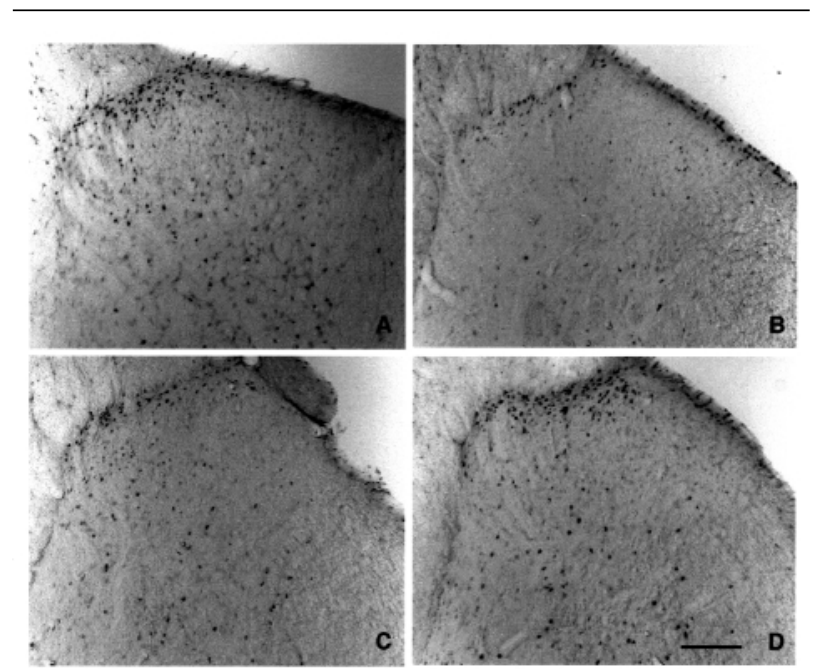

FIGURE 1 Photo micrographs showing c-Fos expression in superficial laminae of the rat

spinal dorsal horn. Scale bar $=200 \mu \mathrm{m} ;$ A, vehicle ten minutes before formalin; B, $0.5 \mu \mathrm{g}$ fentanyl ten minutes before formalin; $\mathrm{C}, 0.5 \mu \mathrm{g}$ fentanyl five minutes after formalin; $\mathrm{D}, 0.5 \mu \mathrm{g}$ fentanyl $60 \mathrm{~min}$ after formalin.

Lower c-Fos expression was observed in laminae III and IV $(8.8 \%$ of the total number of c-Fos expressing cells). There was no statistical difference between controls $(0 \mu \mathrm{g}$ of fentanyl injected rats) in the three groups. On the contralateral side of the injected paw, very few c-Fos expressing cells were found in all rats.

Pretreatment with fentanyl significantly decreased c-Fos expression in a dose-dependent manner in laminae I and II and laminae V and VI in group I (Figures $\mathrm{IB}$ and 2). In laminae III and IV, fentanyl suppressed c-Fos $(23.4 \%$ of control) at the highest dose $(0.5 \mu \mathrm{g})$. These effects were clearly reversed by naloxone (Figure 2). A significant reduction in c-Fos expression was also observed following early post-treatment in group II (Figures IC and 3). These c-Fos suppression were reversed by naloxone (Figure 3 ). However c-Fos suppression in laminae I and II and laminae V and VI at the highest dose of fentanyl $(0.5 \mu \mathrm{g})$ was significantly less in group II than in group I (Figure 4). In group III, no reduction of c-Fos was found in any laminae following late post-treatment with fentanyl (Figures ID and 4).

The reduction in c-Fos levels at $0.5 \mu \mathrm{g}$ of fentanyl in group I was significantly greater in laminae $\mathrm{V}$ and VI ( $14.6 \%$ of control) than in laminae I and II $(32.7 \%$ of control). However the reduction in c-Fos levels in group II was similar in laminae I and II (49.2\% of con- 


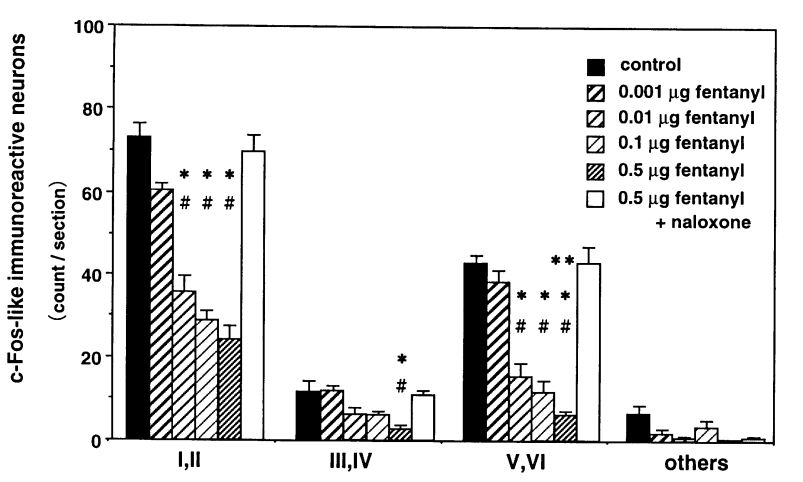

Laminar region

FIGURE 2 Effect of fentanyl administered ten minutes before formalin injection on c-Fos expression in the dorsal horn of rat spinal cord (group I). In laminae I and II, c-Fos expression decreased to $49.0,39.1$ and $32.7 \%$ of control with $0.01,0.1$ and $0.5 \mu \mathrm{g}$ of fentanyl respectively. In laminae III and IV, c-Fos expression decreased to $52.5,51.6$ and $23.4 \%$ of control with $0.01,0.1$ and $0.5 \mu \mathrm{g}$ of fentanyl respectively. In laminae V and VI, c-Fos-LI neurons decreased to $35.9,26.9$ and $14.6 \%$ of control with $0.01,0.1$ and $0.5 \mu \mathrm{g}$ of fentanyl respectively. All data are expressed as mean \pm SEM; $n=5$. \#P<0.01: significant difference compared with control, ${ }^{*} P<0.01$ : significant difference compared with $0.001 \mu \mathrm{g}$ of fentanyl, ${ }^{* *} P<0.01$ : significant difference compared with $0.5 \mu \mathrm{g}$ fentanyl in laminae I and II.

trol), laminae III and IV (50.4\% of control) and laminae V and VI (51.8\% of control; Figure 4). In group $\mathrm{IV}, \mathrm{c}-$ Fos was decreased significantly in laminae $\mathrm{V}$ and VI $(49.0 \%$ of control), although c-Fos was not decreased in laminae I and II (Figure 4). The effects of fentanyl were needed during the early phase of the formalin test to suppress c-Fos expression in laminae $\mathrm{V}$ and VI effectively.

\section{Discussion}

This study demonstrates that both pretreatment and early post-treatment with fentanyl administered intrathecally can suppress c-Fos expression. Furthermore it shows that $\mathrm{c}$-Fos suppression is greater with pretreatment than early post-treatment. In the pretreatment group, c-Fos expression was more profoundly suppressed in laminae $\mathrm{V}$ and VI than in other laminae. Inasmuch as: 1) c-Fos expression can be equated with behavioural changes; 2 ) injection of formalin is an appropriate model of surgical trauma; and 3) animal data can be transports to humans, these results suggest that fentanyl would be an effective pre-emptive analgesic if administered before surgery as well as immediately after commencing surgery.

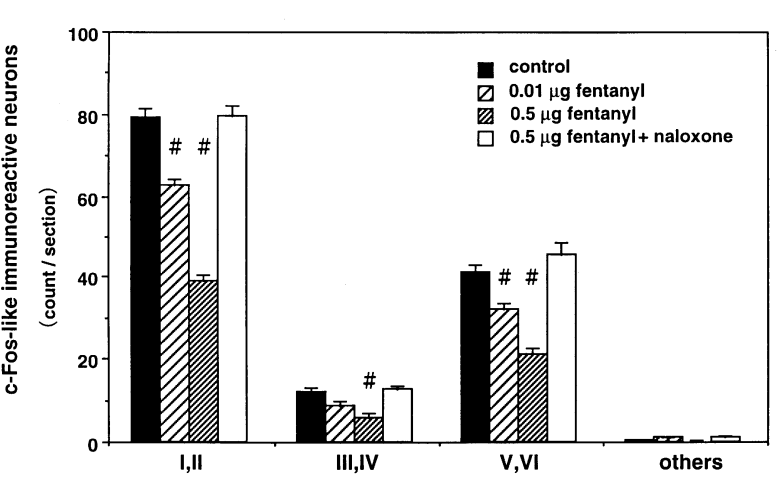

FIGURE 3 Effect of fentanyl administered five minutes after formalin injection on c-Fos expression (group II). In laminae I and II, c-Fos expression decreased to 79.4 and $49.2 \%$ of control with 0.01 and $0.5 \mathrm{ug}$ of fentanyl respectively. In laminae III and IV, cFos expression decreased to 73.9 and $50.4 \%$ of control with 0.01 and $0.5 \mu \mathrm{g}$ of fentanyl respectively. In laminae V and VI, c-Fos expression decreased to 78.3 and $51.8 \%$ of control with 0.01 and $0.5 \mu \mathrm{g}$ of fentanyl respectively. Data are expressed as mean \pm SEM; $n=5$. \# $P<0.01$ : significant difference compared with control.

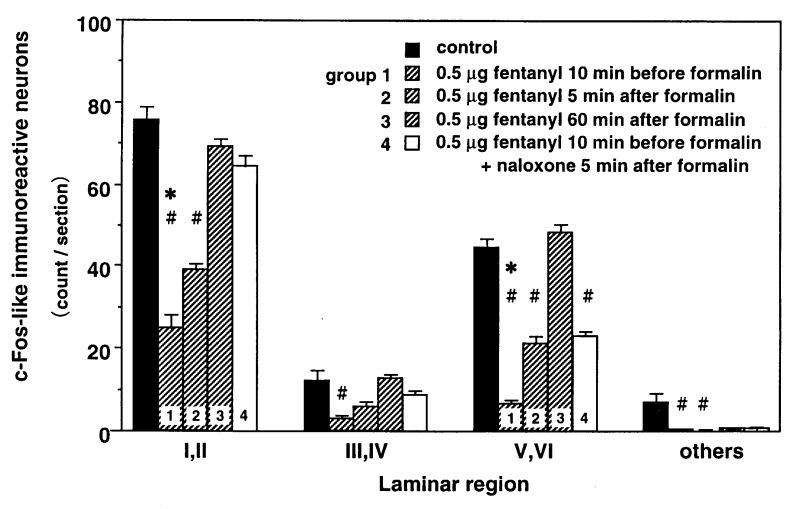

FIGURE 4 Comparisons of all groups which received $0.5 \mu \mathrm{g}$ fentanyl. The value of pretreatment is used as the control for com parison. Data are expressed as mean \pm SEM; $n=5$. $\# P<0.01$ : significant difference compared with control, ${ }^{*} P<0.01$ : significant difference compared with group II ( $0.5 \mu \mathrm{g}$ of fentanyl administered five minutes after formalin injection).

The spinal dorsal horn contains large populations of neurons related to nociceptive transmission ${ }^{9,10}$ and is densely populated with opioid receptors. ${ }^{11}$ The neurons related to nociceptive transmission are also affected by 
opioid-mediated descending control of nociception. ${ }^{12,13}$ Beneficial effects of intrathecal and epidural opioids have been reported. ${ }^{4,14}$ In addition, fentanyl is thought to generate analgesia via opioid receptors in the peripheral site of the primary afferent nerve. ${ }^{15}$

c-Fos is expressed within activated neurons following noxious stimuli and is used as a marker for neuronal activity or sensitization to investigate spinal nociceptive processing. ${ }^{2,16}$ Differential regulation of antinociceptive processing by analgesics, and modulated nociceptive transmission have been shown with cFos expression. ${ }^{7,17}$ Expression of c-Fos is thought to be suppressed via the direct and indirect modulation of nociceptive transmission by fentanyl. Moreover a significant correlation between c-Fos expression and behavioural pain score has been demonstrated. ${ }^{18}$ However this correlation is still controversial, because other studies with analgesics besides opioids reported that c-Fos expression is not always predictive of pain behaviour. ${ }^{19,20}$ This discrepancy is possibly caused by the period those evaluations reflect and by the supraspinal effects that generate analgesia. It is a doubtful point whether spinal c-Fos expression directly correlates with behavioural analgesia that is evaluated as the total effects of supraspinal and spinal regulation to noxious stimuli.

Subcutaneous injection of diluted formalin into rat hind paw produces a biphasic response including an early intense response (early phase) in the first five minutes, and a later moderate response (late phase) that is expressed from 20 to 60 min after injection. ${ }^{18}$ The nociceptive response to formalin is matched by a corresponding biphasic increase in the activity of dorsal horn neurons after injection. ${ }^{21}$ These biphasic reactions are thought to be generated by peripheral and central sensitization after stimulation, which changes the activity of some neurons in the dorsal horn through nociception. ${ }^{1,21}$

Formalin tests have been used as a model of injuryinduced sensitization to study the effect of pre-emptive analgesia. It has been demonstrated that intrathecal pre-administration of opioids abolishes behavioural responses to formalin. ${ }^{22,23}$ The formalin stimulation model, unlike other incisional models, allows the period during which the process of sensitization occurs, and which can be covered by analgesics, to be adjusted easily.

In our study, we showed that fentanyl administered as a pretreatment exerted differential suppression of cFos expression in different laminar regions. These regional differences in c-Fos suppression were not apparent in the post-treatment group. Pretreatment with fentanyl may attenuate temporal summation of noxious input and suppress sensitization of the dorsal horn, thereby reducing the expression of c-Fos in laminae $\mathrm{V}$ and VI more potently than in other laminae.

Certain neurons have specific localizations in the spinal dorsal horn and complex interactions occur between the neurons. For example, wide dynamic range neurons which are located mainly in deep laminae do not normally transmit pain sensation in response to a non-noxious stimulus, while nociceptive specific neurons in superficial laminae always respond to noxious input. However, if wide dynamic range neurons are activated after sensitization, non-noxious stimuli are perceived as pain. ${ }^{22}$ The lamina-specific suppression of c-Fos in the pretreatment group seems to reflect the specific localization of neurons, which have modified their activity or sensitization in response to opioid and formalin injection.

Administration of fentanyl five minutes after formalin injection was not very effective in reducing the activation of a certain population of neurons in deep laminae. This is consistent with these neurons being involved in the early phase of formalin stimulation.

To differentiate between the actions of pretreatment with fentanyl on early and late phase responses to formalin, fentanyl was administered as a pretreatment and then was reversed five minutes after formalin injection (group IV). Fentanyl effectively reduced c-Fos expression in laminae $\mathrm{V}$ and VI suggesting that both phases are necessary for activation of neurons in the dorsal horn and full expression of c-Fos during formalin nociception. Furthermore, fentanyl should suppress c-Fos in deep laminae, at least during the early phase. These regional differences may help explain how preincisional administration of short-acting opioids can cause prolonged suppression of cell activation. ${ }^{23}$

Distribution of c-Fos depends on the nature and course of the noxious stimulus. ${ }^{24,25}$ A comparison of dorsal horn neural activity produced in the two phases after formalin stimulation indicated that each lamina was altered differently. Morphine also suppressed c-Fos expression profoundly in deep laminae when administered prior to formalin stimulation. ${ }^{7}$ A combination of lidocaine and remifentanil also revealed significant regional differences in central activity through formalin stimulation. ${ }^{26}$ Fentanyl, administered at the appropriate time, can suppress c-Fos expression after a noxious stimulus unless it provides a complete block like local anesthetics. Our findings are consistent with clinical and behavioural data reported previously. ${ }^{4,12}$

The benefit of the method used in this experiment is that, with a time course and preserved tissue structure, we can delineate activated neuronal cells following stimulation. Alterations in neuronal activity caused 
by the change in periods covered by a drug can be determined over time by counting of the number of $c$ Fos expressing cells.

Whether all cells always express c-Fos when activated through noxious stimuli should be considered when interpreting results. In our experiment, the effects of fentanyl are compared to maximum c-Fos expression without treatment. Other c-Fos negative neurons, which seem to participate in pain transmission, cannot be detected by our method. In addition, as we examined c-Fos expression at the spinal cord without behavioural evaluation, we cannot directly refer to analgesia observed clinically. This is the first study in which periods covered by the effect of fentanyl were adjusted in relation to formalin stimulation.

In conclusion, intrathecal fentanyl administered immediately after the early phase of formalin stimulus suppresses c-Fos effectively. However, fentanyl should be administered as a pretreatment to suppress neuronal activity at the spinal dorsal horn most effectively. Although formalin injection does not exactly reproduce surgical noxious stimuli and behavioural changes were not examined, the data presented in this experimental study tend to support the concept of pre-emptive effects with a short-acting opioid injected in the subarachnoid space.

\section{Acknowledgement}

We are very grateful to professor Toshikazu Nishimori for his help in perfecting the immunohistochemistory performed in this study.

\section{References}

1 Coderre TJ, Vaccarino AL, Melzack R. Central nervous system plasticity in the tonic pain response to subcutaneous formalin injection. Brain Res 1990; 535: 155-8.

2 Honoré P, Chapman V, Buritova J, Besson J-M. Concomitant administration of morphine and an $\mathrm{N}$ methyl-D-aspartate receptor antagonist profoundly reduces inflammatory evoked spinal c-Fos expression. Anesthesiology 1996; 85: 150-60.

3 Woolf CJ, Chong M-S. Preemptive analgesia - treating postoperative pain by preventing the establishment of central sensitization. Anesth Analg 1993; 77: 362-79.

4 Katz J, Kavanagh BP, Sandlar AN, et al. Preemptive analgesia. Clinical evidence of neuroplasticity contributing to postoperative pain. Anesthesiology 1992; 77: 439-46.

5 Tverskoy $M, O z$ Y, Isakson A, Finger J, Bradley EL Jr, Kissin I. Preemptive effect of fentanyl and ketamine on postoperative pain and wound hyperalgesia. Anesth Analg 1994; 78: 205-9.

6 Yaksh TL, Rudy TA. Chronic catheterization of the spinal subarachnoid space. Physiol Behav 1976; 17: 1031-6.

7 Presley RW, Menétrey D, Levine JD, Basbaum AI Systemic morphine suppresses noxious stimulus-evoked Fos protein-like immunoreactivity in the rat spinal cord. J Neurosci 1990; 10: 323-35.

8 Molander $C, X u Q$ Grant $G$. The cytoarchitechtonic organization of the spinal cord in the rat. I. The lower thoracic and lumbosacral cord. J Comp Neurol 1984; 230: 133-41.

9 Swett JE, Woolf CJ. The somatotopic organization of primary afferent terminals in the superficial laminae of the dorsal horn of the rat spinal cord. J Comp Neurol 1985; 231: 66-77.

10 Besson JM, Chaouch A. Peripheral and spinal mechanisms of nociception. Physiol Rev 1987; 67: 67-186.

11 Atweh SF, Kuhar MJ. Autoradiographic localization of opiate receptors in rat brain. I. Spinal cord and lower medulla. Brain Res 1977; 124: 53-67.

12 Abram SE, Yaksh TL. Morphine, but not inhalation anesthesia, blocks post-injury facilitation. The role of preemptive suppression of afferent transmission. Anesthesiology 1993; 78: 713-21.

13 Fields HL, Basbaum AI. Central nervous system mechanisms of pain modulation. In: Wall PD, Melzack $\mathrm{R}$ (Eds.). Textbook of Pain, 4th ed., New York: Churchill Livingstone Inc., 1999: 309-29.

14 Reuben SS, Dunn SM, Duprat KM, O'Sullivan P. An intrathecal fentanyl dose-response study in lower extremity revascularization procedures. Anesthesiology 1994; 81: 1371-5.

15 Joris JL, Dubner R, Hargreaves KM. Opioid analgesia at peripheral sites: a target for opioids released during stress and inflammation? Anesth Analg 1987; 66: 1277-81.

16 Hunt SP, Pini A, Evan G. Induction of c-Fos-like protein in spinal cord neurons following sensory stimulation. Nature 1987; 328: 632-4.

17 Menétrey D, Gannon A, Levine JD, Basbaum AI. Expression of c-fos protein in interneurons and projec tion neurons of the rat spinal cord in response to somatic, articular, and visceral stimulation. J Comp Neurol 1989; 285: 177-95.

18 Dubuisson D, Dennis $S G$. The formalin test: a quantitative study of the analgesic effects of morphine, meperidine, and brain stimulation in rats and cats. Pain 1977 4: 161-74.

19 Tashpal K, Mason P, Mckenna JE, Sharma SK, Henry $J L$, Coderre TJ. Comparison of the effects of treatment with intrathecal lidocaine given before and after formalin on both nociception and Fos expression in the spinal cord dorsal horn. Anesthesiology 1998; 88 $157-64$ 
20 Girlon I, Quirion R, CoderreTJ. Pre- versus postformalin effects of ketamine or large- dose alfentanil in the rat: discordance between pain behavior and spinal Fos-like immunoreactivity. Anesth Analg 1999; 89: 128-35.

21 Dickenson AH, Sullivan AF. Subcutaneous formalininduced activity of dorsal horn neurons in the rat: differential response to an intrathecal opiate administered pre or post formalin. Pain 1987; 30: 349-60.

22 Siddall PJ, Cousins MJ. Introduction to pain mechanisms. Implications for neural blocakde. In: Cousins MJ, Bridenbaugh PO (Eds.). Neural Blockade in Clinical Anesthesia and Management of Pain, 3rd ed., Philadelphia: Lippincott-Raven Inc., 1998: 675-99.

23 Griffin MJ, Hughes D, Knaggs A, Donnelly MB, Boylan $J F$. Late-onset preemptive analgesia associated with preincisional large-dose alfentanil. Anesth Analg 1997; 85: 1317-21

24 Williams S, Evan GI, Hunt SP. Changing patterns of c fos induction in spinal neurons following thermal cuta neous stimulation in the rat. Neuroscience $1990 ; 36$ : 73-81.

25 Herdegen T, Kovary K, Leah J, Bravo R. Specific temporal and spatial distribution of JUN, FOS, and KROX-24 proteins in spinal neurons following noxious transsynaptic stimulation. J Comp Neurol 1991; 313: 178-91.

26 Abbadie C, Taylor BK, Peterson MA, Basbaum AI. Differential contribution of the two phases of the formalin test to the pattern of $\mathrm{c}$-fos expression in the rat spinal cord: studies with remifentanil and lidocaine. Pain 1997; 69: 101-10. 